\title{
Rancang Bangun Alat Pengukur Langkah Kaki dengan Sensor Accelerometer dan Fasilitas Komunikasi Wireless 2,4 GHz
}

\author{
Muslim Abadi ${ }^{1}$, Akuwan Saleh ${ }^{2}$ \\ ${ }^{1}$ Politeknik Elektronika Negeri Surabaya, Jurusan Teknik Telekomunikasi \\ ${ }^{2}$ Politeknik Elektronika Negeri Surabaya Institut Teknologi Sepuluh Nopember \\ Kampus ITS, Surabaya 60111 \\ e-mail :21muslim@gmail.com, e-mail : akuwan@eepis-its.edu
}

\begin{abstract}
Abstrak
Penggunaan ilmu pengetahuan dan teknologi semakin meningkat terutama dibidang elektronika dan telekomunikasi. Salah satunya dengan dengan berbagai macam penggunaan sensor accelerometer dan sistem komunikasi 802.15.4 (ZigBee) secara wireless. Contohnya dalam pengiriman data langkah kaki manusia pada frekuensi $2,4 \mathrm{GHz}$ menggunakan sensor accelerometer H48C. Pada proyek akhir ini, suatu sistem pengukuran langkah kaki manusia dengan sensor accelerometer H48C yang dikontrol oleh mikrokontroler AVR Low Cost Mikro System (ATmega8535) dimana datanya dikirim secara wireless menggunakan XbeePRO pada frekuensi 2,4 GHz.

Pada paper ini telah dilakukan pembacaan data yang didapat dari sensor H48C yang diolah dengan mikrokontroler ATmega8535 dan hasilnya dikirim ke sisi receiver melalui wireless menggunakan XbeePRO pada frekuensi 2,4 GHz. Sehingga dapat diketahui data langkah kaki manusia berupa jarak, jumlah langkah waktu dan kecepatan. Dari hasil pengolahan data dapat. Disisi receiver tampilan akan menggunakan software visual basic 6.0.
\end{abstract}

Kata Kunci : Radio Frekuensi Tranceiver, Mikrokontroler, Sensor.

\section{PENDAHULUAN}

Seiring berkembangnya teknologi di bidang telekomunikasi, maka kebutuhan efisiensi kerja semakin bertambah besar. Masalah jarak dan waktu tidak akan menjadi penghalang yang berarti. Untuk para pejalan kaki yang merasa ingin memantau langkah kakinya adanya perangkat elektronika berupa sensor accelerometer sangat membantu untuk memantau langkah kaki seseorang. Karena objek selalu bergerak dalam hal pengiriman informasi tidak dimungkinkan menggunakan kabel yang panjang. Oleh karena itu, proyek akhir ini dibuat tentang rancang bangun alat pengukur langkah kaki secara nirkabel menggunakan sensor accelerometer dengan fasilitas wireless pada frekuensi 2,4 GHz.

Xbee-PRO yang bertindak sebagai piranti komunikasi wireless ini akan mengirim data dari sensor yang telah diinputkan ke mikrokontroler DT AVR Low Cost Mikro System (ATmega8535) saat menerima gerakan dari langkah kaki. Data yang dikirim oleh transmitter pada sisi pemakai sensor adalah jumlah langkah kaki, jarak yang ditempuh, dan panjang langkah per step. Data tadi selanjutnya akan ditampilkan pada perangkat komputer pada sisi receiver dengan membuat aplikasi dari bahasa visual basic 6.0.

\section{TEORI PENUNJANG}

2.1 Sistem Komunikasi Wireless

Komunikasi wireless adalah suatu sistem komunikasi pada suatu jaringan yang menggunakan gelombang radio sebagai media transmisi. Wireless sering disebut juga dengan nirkabel atau tanpa kabel. Biasanya wireless ini dipakai di suatu daerah atau lokasi dimana pemakainya selalu dalam keadaan bergerak, atau dilokasi tersebut tidak terdapat jaringan kabel untuk penyaluran data. Sistem wirelesss yang akan dibangun pada proyek akhir ini akan menggunakan frekuensi $2,4 \mathrm{GHz}$ yang disebut juga dengan ISM (Industrial, scientific, Medical) Band, dimana oleh FCC (Federal Communication Commision) memang dialokasikan untuk berbagai keperluan industri, sains dan media.

\subsection{Theorema Segitiga}

Segitiga adalah nama suatu bentuk yang dibuat dari tiga sisi yang berupa garis lurus dan tiga sudut. Matematikawan Euclid yang hidup sekitar tahun 300 SM menemukan bahwa jumlah ketiga sudut di suatu segi tiga adalah 180 derajat. Hal ini memungkinkan kita 
menghitung besarnya salah satu sudut bila dua sudut lainnya sudah diketahui.

Aturan kosinus, dalam trigonometri adalah aturan yang memberikan hubungan yang berlaku dalam suatu segitiga, yaitu antara panjang sisi-sisi segitiga dan kosinus dari salah satu sudut dalam segitiga tersebut. Aturan ini nanti akan diterapkan pada peralatan untuk menghitung jarak langkah kaki, jenis segitiga yang digunakan adalah segitiga sama kaki dimana sudut yang didapat dari peralatan ialah sudut pangkal paha dan panjang sisi miring ialah panjang kedua kaki serta alas ialah jarak yang ditempuh. Gambar 1 dibawah ini akan menjelaskan bagaimana kondisi saat melangkah.

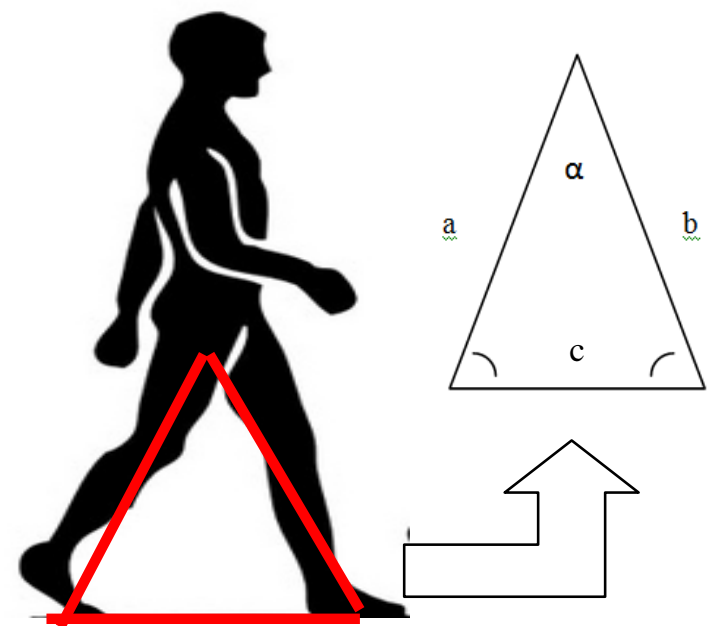

Gambar 1 Kondisi manusia saat melangkah

Gambar diatas adalah kondisi dimana manusia saat melangkah yang membentuk sudut $\alpha$ atau sudut pangkal paha. Panjang kaki manusia umumnya adalah sama oleh karena itu $\mathrm{a}=\mathrm{b}$. Sudut $\alpha$ dapat dihitung menggunakan sensor accelerometer yang bekerja berdasarkan sudut kemiringan kaki. Karena nilai $\alpha$, a dan $b$ diketahui, maka untuk memperoleh c (panjang alas) dapat digunakan aturan kosinus :

$$
c=\sqrt{a^{2}+b^{2}-2 a b \cos \tilde{\Sigma} \alpha}
$$

\subsection{DT AVR Low Cost Micro System ATmega8535}

AVR merupakan seri mikrokontroler CMOS 8-bit buatan Atmel, berbasis arsitektur RISC (Reduced Instruction Set Computer). Hampir semua instruksi dieksekusi dalam satu siklus clock. AVR mempunyai 32 register general-purpose, timer/counter fleksibel dengan mode compare, interupt internal dan eksternal, serial UART, programmable Watchdog Timer, dan mode power saving.. AVR juga mempunyai In-System Programmable Flash on-chip yang mengijinkan memori program untuk diprogram ulang dalam sistem menggunakan

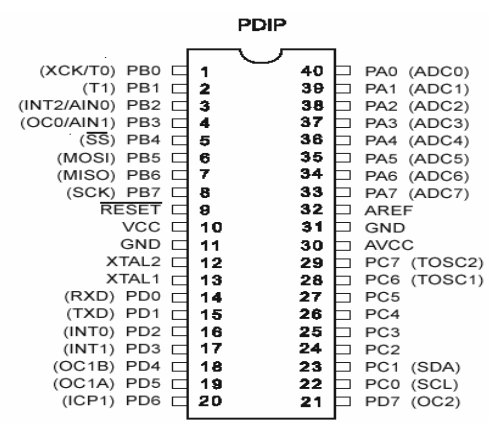

hubungan serial SPI.

Gambar 2 Pin ATmega8535

\subsection{Sensor Accelerometer H48C}

Accelerometer adalah perangkat yang digunakan untuk mengukur akselerasi dan dampak gravitasi pada percepatan. Sensor accelerometer 3 axis ini memiliki beberapa sifat yang ada karena kemampuannya merepresentasikan tiga buah sumbu. Beberapa sifat tersebut adalah roll, pitch dan yaw. Sifat ini merupakan sifat pergerakan terhadap sumbu $\mathrm{X}, \mathrm{Y}$ dan $\mathrm{Z}$ yang telah disesuaikan dengan titik gravitasi bumi. Sumbu $X$ merepresentasikan gerakan perputaran. Sumbu Y merepresentasikan gerakan terhadap kemiringan pada sumbu Y .Sumbu Z merepresentasikan gerakan menoleh atau perbelokan terhadap bidang.

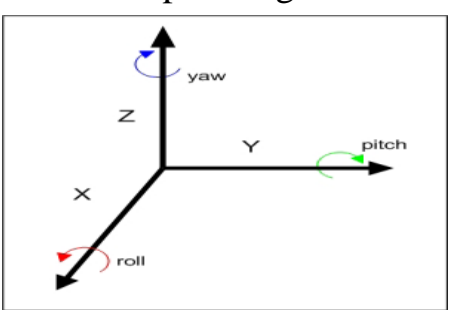

Gambar 3 Analogi sumbu pada 3-axis accelerometer

H48C adalah modul sensor accelerometer terintegrasi yang berbahan dasar silicon yang dapat merasakan gaya gravitasi dan merepresentasikannya dalam tiga buah sumbu angular (X, Y, dan Z). Pada modul ini terdapat regulator tegangan untuk mensuplai tegangan 3.3 volt untuk chip H48C, 12-bit ADC jenis MCP3204 untuk membaca tegangan keluaran dari chip H48C. 


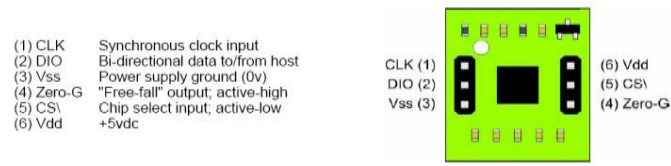

Gambar 4 Pin H48C onboard

Prinsip kerja sensor ini adalah seperti di tunjukkan oleh gambar 5. Sensor menghasilkan panas yang mana jika dimiringkan maka panas tersebut akan memanasi bagian pinggir sensor yang merupakan bahan seperti thermocoupler. Sehingga jika dipanaskan akan menghasilkan perubahan dan perbedaan panas yang mengakibatkan terjadinya perubahan tegangan yang nantinya dimasukkan kedalam ADC
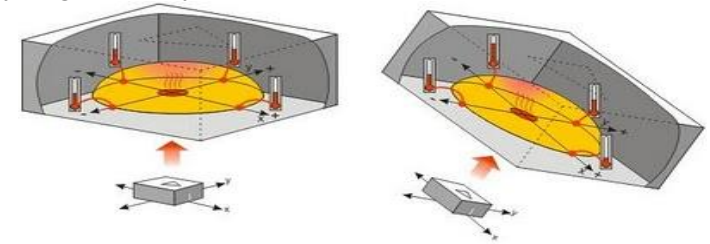

Gambar 5 Prinsip kerja accelerometer

\subsection{Xbee-PRO Modul RF Tranceiver}

Xbee-PRO merupakan modul RF yang didesain dengan standard protocol IEEE 802.15.4 dan sesuai dengan kebutuhan sederhana untuk jaringan wireless. Kelebihan utama yang menjadikan Xbee-PRO sebagai komunikasi serial nirkabel karena Xbee-PRO memiliki konsumsi daya yang rendah yaitu hanya 3,3 V. Modul ini beroperasi pada rentang frekuensi $2,4 \mathrm{GHz}$

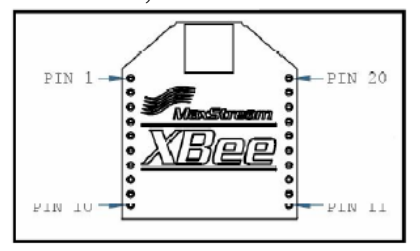

Gambar 6 Pin Xbee-PRO

Dalam melakukan komunikasi dengan perangkat lainnya Xbee-PRO mampu melakukan komunikasi dengan dua macam komunikasi yang berbeda, tergantung dari perangkat apa yang dihubungkan dengan modul Xbee-PRO. Komunkasi dapat dilakukan dengan menggunakan jaringan wireless dan komunikasi secara serial

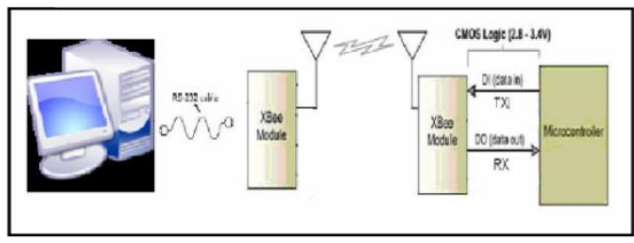

Gambar 7 Komunikasi serial Xbee-PRO

\section{METODOLOGI \\ 3.1 Perancangan Sistem}

Perancangan sistem pada proyek akhir ini, dibagi menjadi 2, yaitu perancangan hardware dan software. Untuk blok diagram bias dilihat pada gambar 8 .

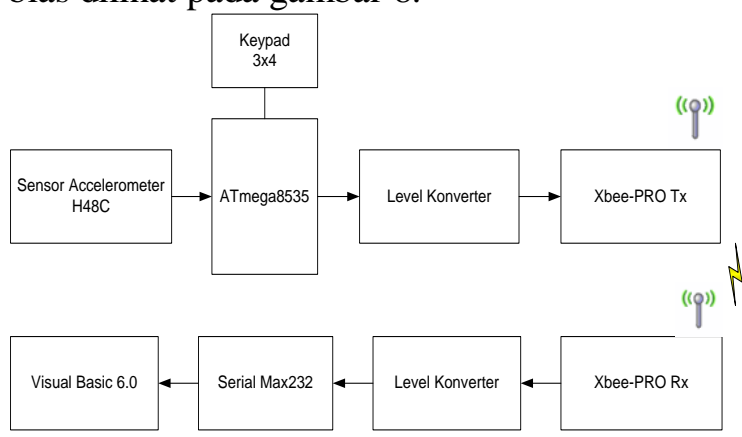

Gambar 8 Blok diagram Sistem

Gambar 8 merupakan sistem keseluruhan yang akan dibangun pada proyek akhir ini. Dimana nantinya sistem ini akan bisa memperoleh data dari langkah kaki seseorang. Sistem ini terbagi atas dua bagian yaitu blok sistem transmitter dan blok sistem receiver. Pada tiap-tiap blok terdapat beberapa peralatan, pada blok sistem transmitter terdiri dari sensor 3-axis accelerometer $\mathrm{H} 48 \mathrm{C}$ yang berfungsi sebagai data masukan langkah kaki, modul mikrokontroler ATmega8535 yang merupakan peralatan pengontrol utama, rangkaian konverter untuk mengubah tegangan dan Xbee-PRO yang diset sebagai transmitter yang akan mengirimkan data ke sistem receiver. Dan pada blok sistem receiver terdiri dari Xbee-PRO yang akan di-set sebagai receiver, rangkaian level konverter untuk mengubah tegangan. Gambar dibawah ini adalah blok rangkaian transmitter untuk mengukur langkah.

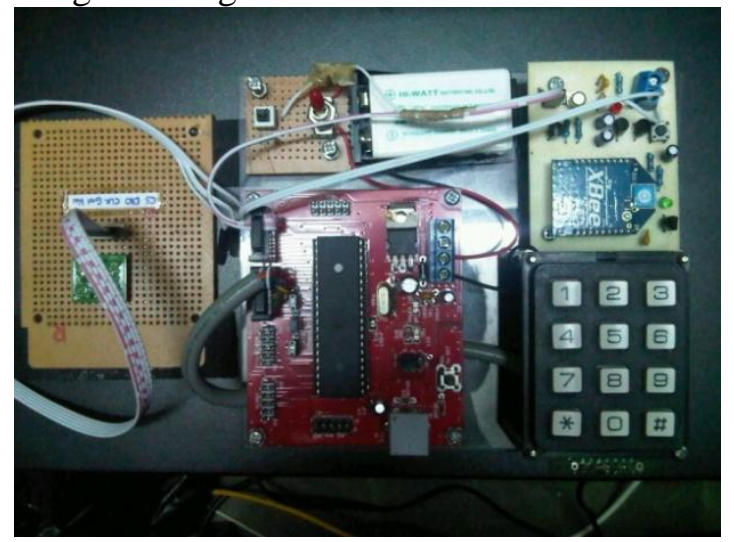

Gambar 9 Rangkaian pengukur langkah 
Flowcard dibawah ini merupakan langkah-langkah peralatan supaya bisa memproses dan menghitung langkah kaki.

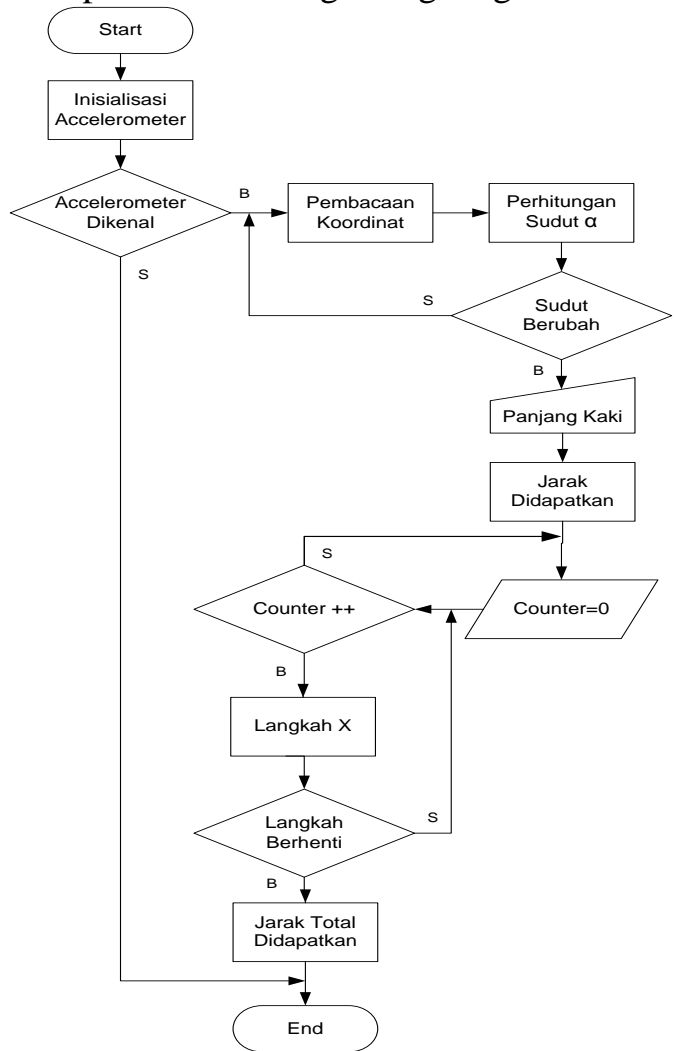

Gambar 10 Flowchard sistem pengukur langkah

Mikrokontroler menerima masukan data dari sensor accelerometer. Mula-mula proses inisialisasi accelerometer, maka apakah accelerometer dikenal jika tidak dikenal proses akan berakhir, jika dikenal akan ada proses looping berupa respon pembacaan untuk masing-masing sudut dari accelerometer. Dari variabel yang diperoleh pada sumbu X, akan diolah supaya bisa memperoleh nilai sudut $\alpha$, dari sudut yang didapat tadi apakah ada perubahan jika tidak ada maka akan kembali menghitung koordinat, jika ada perubahan sudut jerak bisa diketahui. Untuk menghitung jarak langkah perlu terlebih dahulu diberikan input berupa panjang kaki pengguna yang berasal dari keypad 3x4. Setelah jarak telah didapat nilai counter diset 0 , lalu adakah counter tadi bertambah jika tidak maka counter akan tetap 0, dan jika counter bertambah maka langkah kaki didapat. Setelah itu apakah langkah kaki berhenti jika tidak counter akan terus bertambah hingga langkah berhenti, jika counter tidak bertambah maka jarak total bisa didapatkan.

\subsection{Desain Mekanik Sistem}

Perangkat yang dipakai untuk pengukuran akan didesain supaya lebih efektif dan fleksibel supaya bisa mengoptimalkan kinerja alat. Desain penempatan sistem transmitter berada ditubuh pengguna. Untuk sensor accelerometer penempatanya adalah pada bagian paha depan dari objek sedangkan penempatan mikrokontroler dan Xbee-PRO Tx diikatkan disekitar pinggang. Sedangkan untuk desain sistem receiver peralatan ditempatkan disekitar perangkat komputer.

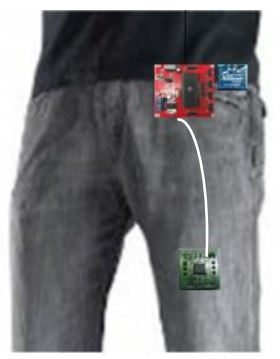

Gambar 11 Desain mekanik rancangan sistem

\section{$4 \quad$ Pengujian dan Analisa \\ 4.1 Pengujian dan Pengukuran Rangkaian Xbee-PRO}

Pada proyek akhir ini telah dibuat rangkaian hardware dan software yang dipakai. Pada sistem ini Xbee-PRO dihubung pada rangkaian yang fungsinya adalah sebagai pengatur tegangan bagi Xbee-PRO dan pada rangkaian ini akan menghubungkan Tx dan $\mathrm{Rx}$ ke perangkat embedded yang dituju. Pada rangkaian ini terdapat indikator power serta indicator ketika Xbee-PRO menerima data dari Xbee-PRO yang lain.

Untuk melakukan setting pada XbeePRO diperlukan software yang dapat berhubungan dengan media serial dengan IC MAX232 yang terkoneksi dengan Xbee-PRO. Software yang dapat digunakan untuk penyetingan adalah X-CTU.

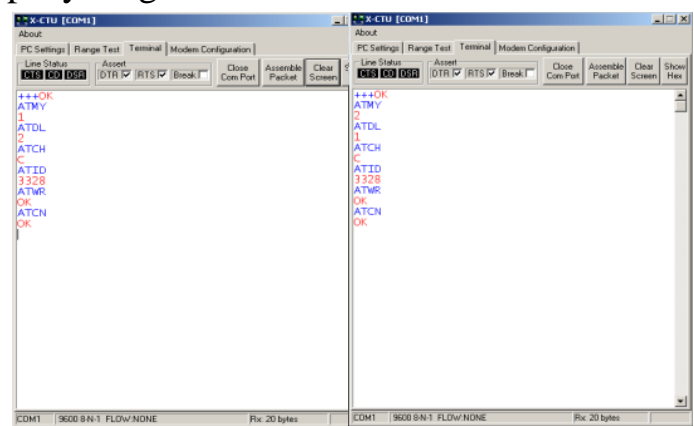

Gambar 12 Setting konfigurasi Xbee-PRO 
Pengujian ini dilakukan dilaboratorium microwave E-306 D4 lantai 3, inputan transmitter berasal dari keypad rubber $3 \times 4$ pada PORTC mikrokontroler, yang diterima oleh rangkaian receiver yang terkoneksi oleh PC di dalam ruangan laboratorium proyek akhir gedung D4 lantai 4 E- 306 dengan menggunakan software Visual Basil 6.0. Dari hasil pengukuran dengan lokasi transmitter yang berbeda-beda (bergerak) didapat pengukuran berikut.

Tabel 1 Tabel Pengukuran Coverage XbeePRO

\begin{tabular}{|c|c|c|}
\hline Posisi transmitter & $\begin{array}{c}\text { Jarak } \\
(\mathbf{m})\end{array}$ & $\begin{array}{c}\text { Status } \\
\text { Pengiriman }\end{array}$ \\
\hline $\begin{array}{l}\text { lab propagasi gelombang } \\
\text { radio (E-305) }\end{array}$ & 3 & Terkirim \\
\hline $\begin{array}{c}\text { lab jaringan komputer } \\
\text { (C-307) }\end{array}$ & 35 & Terkirim \\
\hline $\begin{array}{l}\text { lab pemrograman } \\
\text { komputer } 2(\mathrm{C}-303)\end{array}$ & 63 & Terkirim \\
\hline $\begin{array}{c}\text { lab automatisasi pabrik } \\
\text { (D-303) }\end{array}$ & 63 & Terkirim \\
\hline $\begin{array}{l}\text { lab komputer dan } \\
\text { antarmuka (D-306) }\end{array}$ & 35 & Terkirim \\
\hline kelas (B-303) & 57 & Terkirim \\
\hline lab DSP (E-206) & 8 & Terkirim \\
\hline $\begin{array}{l}\text { lab Komunikasi dan } \\
\text { simulasi (C-206) }\end{array}$ & 39 & Terkirim \\
\hline $\begin{array}{l}\text { lab pemrograman } \\
\text { komputer } 2(\mathrm{C}-203)\end{array}$ & 70 & Terkirim \\
\hline Kelas (B-202) & 62 & Terkirim \\
\hline $\begin{array}{c}\text { lab pengukuran listrik } \\
\text { (D-203) }\end{array}$ & 70 & Terkirim \\
\hline $\begin{array}{l}\text { lab kontrol otomatis } \\
\text { (D-206) }\end{array}$ & 39 & Terkirim \\
\hline $\begin{array}{c}\text { lab pemrograman } \\
(\mathrm{C}-105)\end{array}$ & 44 & Terkirim \\
\hline $\begin{array}{c}\text { lab jaringan telefoni } \\
(\mathrm{E}-107)\end{array}$ & 16 & Terkirim \\
\hline $\begin{array}{l}\text { lab pemrograman } \\
\text { komputer }(\mathrm{C}-102)\end{array}$ & 76 & Terkirim \\
\hline $\begin{array}{c}\text { depan perpustakaan D4 } \\
(\text { Hall D4 lnt 1) }\end{array}$ & 68 & Terkirim \\
\hline $\begin{array}{l}\text { lab sistem tenaga dan } \\
\text { mesin listrik (D-103) }\end{array}$ & 76 & Terkirim \\
\hline $\begin{array}{l}\text { lab kontrol cerdas dan } \\
\text { robotic (D-104) }\end{array}$ & 44 & Terkirim \\
\hline
\end{tabular}

\subsection{Pengujian Sensor Accelerometer H48C}

Pada proyek ini sensor yang digunakan untuk mengukur langkah adalah
Hitachi H48C 3-axis accelerometer. Tujuan dipilihnya sensor ini adalah karena karakteristik dan cara kerja sensor berdasarkan derajat kemiringan benda terhadap permukaan bumi. Sensor ini akan dipasang dan diikat paha bagian paha user dimana ketika melangkah paha akan membentuk sudut segitiga sama kaki.

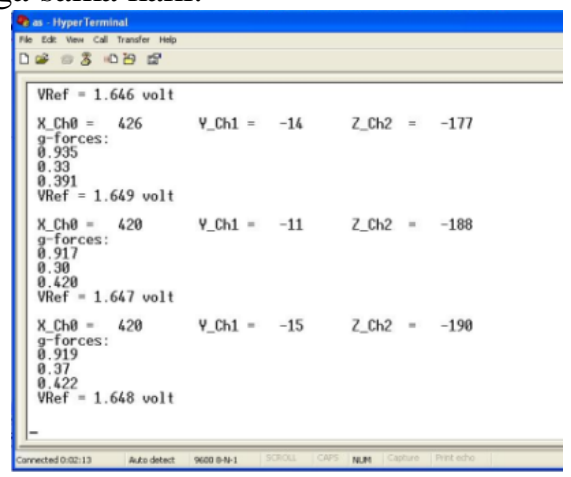

Gambar 13 Hasil pembacaan sensor

\subsection{Analisa Pengukuran Jumlah Langkah Kaki}

Pengukuran dilakukan pada pengguna yang memakai sensor pada paha depan. Sensor akan mulai menghitung Jumlah langkah kaki, ketika mengalami kemiringan yang berarti, artinya pada saat melangkah kaki akan berayun dengan kemiringan tertentu. Jumlah langkah ini akan dianalisa dan dibandingkan dengan langkah kaki perhitungan manual saat berjalan. Grafik hasil pengukuran dapat dilihat pada gambar 14 dibawah ini.

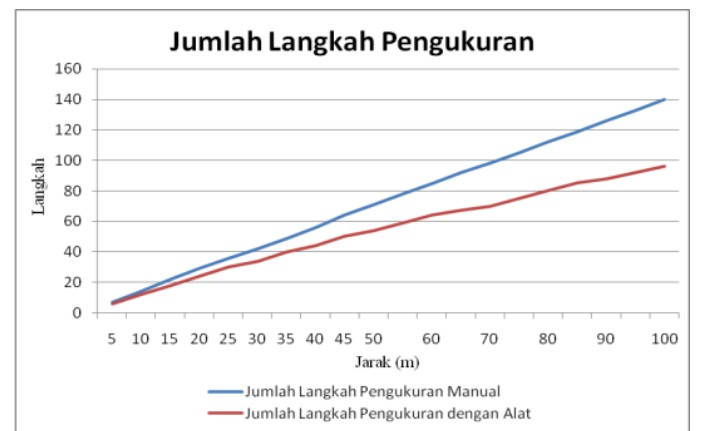

Gambar 14 Grafik perbandingan jumlah langkah kaki

Dari grafik diatas dapat dilihat hasil pengukuran keduanya terlihat tampak berbeda, dimana kondisi saat mengukur dengan alat semakin jauh jarak tempuh maka hasilnya semakin menjauhi nilai pengukuran langkah ketika diukur secara 
manual. Hal ini dikarenakan modul wireless Xbee-PRO mengalami peredaman ketika jarak yang ditempuh semakin jauh.

\subsection{Analisa Pengukuran Jarak Total}

Pada pengujian kali ini akan dibahas mengenai jarak total pengukuran yang ditempuh oleh pemakai sensor. Pengukuran jarak pada peralatan didapatkan pada sensor accelerometer ketika mengalami kemiringan dan variabel pada sumbu $\mathrm{x}$ berubah, dari perubahan tadi akan dihitung jarak perstepnya. Dimana ketika langkah berhenti dan switch dalam kondisi off maka jarak total bisa dihitung. Hasil pengukuran dapat dilihat pada gambar 15 .

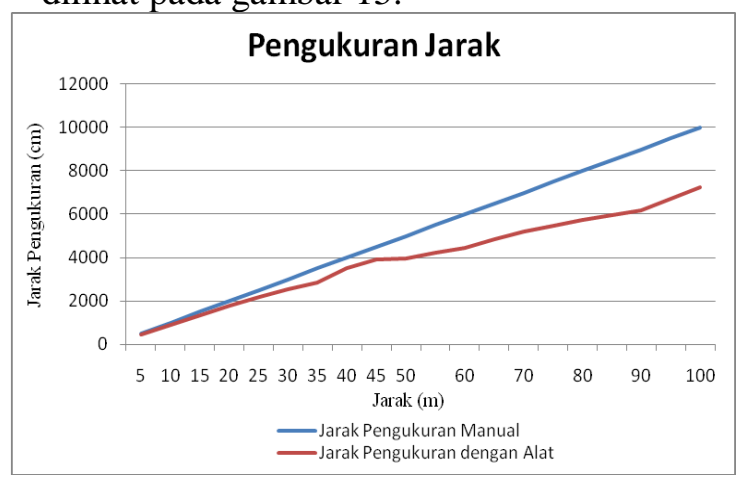

Gambar 15 Grafik perbandingan pengukuran jarak

\subsection{Analisa Pengukuran Kecepatan}

Pada bagian ini akan dianalisa kecepatan langkah kaki ketika berjalan. Dari hasil pengukuran jarak yang telah diketahui tadi dapat dihitung kecepatan langkah kaki dengan rumus kecepatan adalah jarak total dibagi waktu, dengan waktu didapat dari stopwatch. Hasil perhitungan kecepatan dapat dilihat pada gambar 16 dibawah ini.

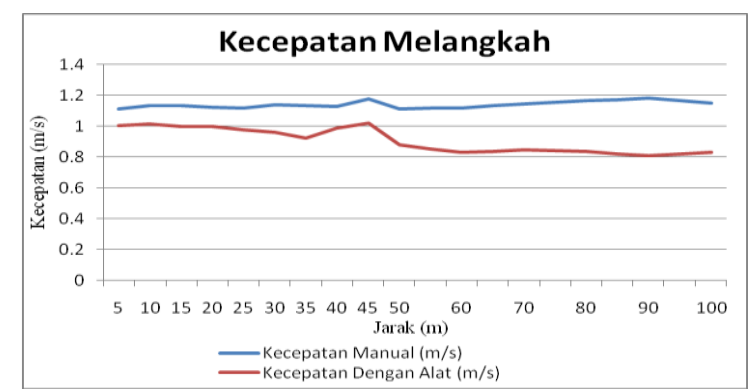

Gambar 16 Grafik perbandingan kecepatan langkah

\section{Kesimpulan}

Dari hasil penelitian terhadap sistem yang telah dibuat ini dapat disimpulkan antara lain :

1. Hasil pengukuran berupa jumlah langkah kaki, jarak yang didapat dan kecepatan yang dihasilkan sensor accelerometer cenderung menurun pada jarak yang sama, hal ini dikarenakan data yang dikirimkan ke receiver mengalami redaman.

2. Prosentase error yang dihasilkan oleh peralatan melebihi 10 persen dan kurang dari 40 persen.

3. Sensor accelerometer H48C memberikan respon ketika alat tersebut dalam kondisi mengalami perubahan sudut pada 3 buah sumbu.

4. Keypad rubber $3 \times 4$ bekerja seperti push button tetapi pembacaannya berupa baris dan kolom.

\section{Daftar Pustaka}

[1] Ary Heryanto., Wisnu Adi P., "Pemrograman Bahasa C untuk Mikrokontroler ATMEGA8535", ANDI, Yogyakarta, 2008.

[2] Dimas Lazuardi Adya Putra., "Rancang Bangun Perangkat Keras Joystick PC Interaktif Untuk Aplikasi Permainan enis FPS(First Person Shooter) dengan mokrokontroler dan sistem komunikasi 802.15.4", PENSITS, Juli 2009.

[3] Gilang Kharisma, "Perancangan dan Pembuatan Perangkat Keras Untuk Pemantau Kondisi Hujan dengan Sistem Komunikasi 80215.4(Zigbee)", PENS-ITS, Juli 2009.

[4] Xbee-pro data sheet http://www.digi.com/products/wireless /pointmultipoint/xbee-seriesmodule .jsp

[5] Referensi Proyek akhir corell university http://courses.cit.cornell.edu/ee476/Fi nalProjects/s2008/hc454_pl328/hc454 _pl328/index.html

[6] Cara Kerja Accelerometer H48C. http://keep-elka.blogspot.com/2010/ 01/rangkaian-parallax-hitachi-3g-triaxis.html 